\title{
Un TALLER DE FALSARIOS EN LA CUEVA DE LA TORRE DEL Mal Paso (Castellnovo, Castellón)
}

La Cueva de la Torre del Mal Paso se halla a unos 400 m.s.n.m en la ladera W del cerro de La Torreta (Castellnovo, Castellón), a pocos metros del poblado ibérico del mismo nombre (Ballester 1946; 1947; 1948; 1949). Los materiales objeto del presente estudio, depositados en el Museu de Prehistòria de València, son el resultado de las excavaciones realizadas entre los años 1946 y 1947, campañas que evidenciaron una frecuentación continuada de la cavidad a partir del Calcolítico y la Edad del Bronce, cuando fue utilizada como lugar de enterramiento. Otros usos rituales y de diversa índole tuvieron lugar durante las épocas ibérica, romana, medieval y moderna (Fletcher 1954; Jordá 1958; Soler 2002).

La revisión de estos materiales, inscrita en la tesis doctoral de uno de los autores, ha permitido documentar la existencia de un taller de falsificación monetaria del s. XVII. Los recortes metálicos hallados en varios niveles de los cinco sectores en los que se dividió la excavación, fueron interpretados como posibles restos de postas, cartuchos o carga de trabuco (Fletcher 1954: 216). Tras la revisión del yacimiento se ha podido comprobar que estos fragmentos metálicos se vieron afectados por la remoción natural que alteró, tanto a los niveles superiores de los sectores E, C, A y B, como a la totalidad de niveles del sector D situado al fondo de la cueva (fig. 1). Así pues, los materiales relacionados con falsificaciones del s. XVII se documentan tanto en la entrada de la cueva (sectores E-C, nivel 1), como en la parte central (sector $\mathrm{A}$, nivel 4 y sector $\mathrm{B}$, niveles 1-3) y en el último tercio de la cavidad, donde la remoción está presente en la totalidad de los niveles excavados (sector D, niveles 1-9) (Fletcher 1954; Jordá 1958). En la cueva se encontraron también 22 monedas imperiales, entre las que predominan bronces de los antoninos y piezas de la primera mitad del s. III d.C. (Mateu y Llopis 1955: 135; Fletcher 1954: 220-221).

\section{LAS PRUEBAS DE UNA ACTIVIDAD ILEGAL}

El conjunto de materiales relacionados con la actividad de falsarios está compuesto por 477 fragmentos, con un peso total de 262,17 g (MPV 8023-8028, 42283$42323^{1}$ ). El material se ha organizado en seis grupos atendiendo a sus características formales (fig. 2): cuatro monedas, que incluyen una pieza oficial y tres imitaciones (cat. 1-4; fig. 3), 84 cospeles de forma redondeada (cat. 5-18; fig. 3), 270 cospeles con recorte cuadrangular (cat. 19-31; figs. 3 y 4), 40 recortes que incluyen algún borde cóncavo (cat. 32-39; fig. 4), 63 rieles (cat. 40-50; figs. 4 y 5) y 16 formas diversas que no encajan con claridad en ninguna de las agrupaciones anteriores (cat. 51-57; fig. 5). 


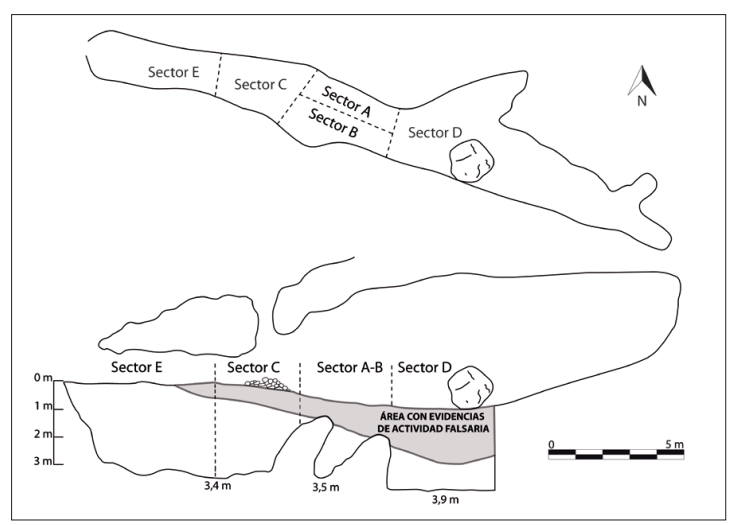

Fig. 1. Planta y sección de la cavidad a partir de Fletcher (1954: fig. 2), Jordá (1958: fig. 2) y Soler (2002: fig. 14).

\begin{tabular}{|l|c|c|c|}
\hline & $(\mathrm{n})$ & Peso total $(\mathrm{g})$ & Peso medio $(\mathrm{g})$ \\
\hline Monedas & 4 & 2,57 & 0,64 \\
\hline Cospeles & 84 & 34,7 & 0,41 \\
\hline Recortes cuadrangulares & 270 & 91,13 & 0,34 \\
\hline Recortes bordes cóncavos & 40 & 15,34 & 0,38 \\
\hline Rieles & 63 & 42,87 & 0,68 \\
\hline Varios & 16 & 75,56 & 4,72 \\
\hline Total & 477 & 262,17 & \\
\hline
\end{tabular}

Fig. 2. Resumen de los fragmentos hallados.

La mayoría de piezas presentan un grosor aproximado de $1 \mathrm{~mm}$, aunque algunos fragmentos alcanzan 2-3 mm. Sus pesos son notablemente variados. Las monedas de imitación pesan algo menos que la única pieza oficial recuperada. Los pesos más comunes de los cospeles redondeados oscilan entre los 0,15 y los $0,80 \mathrm{~g}$ y sus diámetros se encuentran entre los 8 y los $15 \mathrm{~mm}$. Los recortes cuadrangulares, de unos 8-10 mm, tienen un peso de 0,20-0,30 g, y los de $12 \mathrm{~mm}$ alcanzan los 0,30-0,75 g. Los recortes con bordes cóncavos pesan entre 0,20 y $0,90 \mathrm{~g}$. La longitud mínima documentada es de $10 \mathrm{~mm}$, mientras la máxima alcanza los $50 \mathrm{~mm}$. En el caso de los rieles, el peso oscila desde los 0,35 g hasta los 1,95 g aunque alguno más grueso alcanza hasta $4,23 \mathrm{~g}$, pero constituye una excepción. La longitud de éstos fluctúa entre los 15 y los $80 \mathrm{~mm}$, mientras que su anchura se encuentra entre 2 y $10 \mathrm{~mm}$.

El material recuperado apunta hacia el empleo de dos técnicas diferentes de recorte. Por un lado se obtenían cospeles circulares (cat. 5-18; fig. 3) a partir del recorte de pequeñas laminas cuyos bordes cóncavos testimonian este proceder (cat. 32-39; fig. 4), mientras que por otro lado los rieles (cat. 40-50; figs. 4 y 5) se troceaban longitudinalmente dando como resultado pequeños recortes cuadrangulares (cat. 19-31; figs. 3 y 4). Resulta complicado averiguar si dichas diferencias se originaron como resultado de fases sucesivas, del trabajo de equipos distintos, si respondieron a finalidades diversas, o si únicamente son consecuencia de una adaptación a la materia prima disponible. Las piezas redondeadas y los recortes cóncavos son similares a los procedentes de Monte Zamora en la Vall d'Uixó, taller donde no se documentan los rieles y los recortes cuadrangulares (Sendra y Rodrigo 2011-2012: 229-231). La excavación de la Cova de l'Águila en Picassent, por el contrario, proporcionó numerosos rieles y recortes cuadrangulares que se martilleaban para darles una forma redondeada (Ripollès 1993: 286-289), pero entre sus numerosos hallazgos no se registró ningún fragmento con borde cóncavo.

\section{LA FALSIFICACIÓN EN CUEVAS}

La imitación de moneda en época moderna fue una práctica extendida en toda la península Ibérica, atribuyéndose tradicionalmente a colectivos determinados como banqueros, mercaderes extranjeros y grupos minoritarios foráneos como moriscos, especialmente en el Reino de Valencia, y franceses (Estrada-Rius 2012: 265). De hecho en Valencia, se impusieron hasta penas de muerte para intentar controlar estas prácticas falsarias ampliamente generalizadas, que constituyeron un verdadero problema económico. Testimonios arqueológicos y documentales demuestran que estas actividades se realizaban en lugares alejados y aislados de los núcleos de población como bosques, grutas, cuevas o abrigos (Sendra y Rodrigo 2010-2011; Torres 2012).

Aunque fue a comienzos del siglo XVII cuando este fenómeno cobró particular fuerza, lo que dio pie a la promulgación del conocido edicto del Marqués de Caracena de 1609 (Lluis y Navas-Brusi 1955: 107-108), resulta complicado proponer una cronología concreta para estos hallazgos. Al igual que muchas otras cuevas de territorio valenciano, la del Mal Paso reúne los materiales utilizados en el proceso de falsificación. Vestigios de esta actividad ilícita en otros yacimientos revelan un patrón muy similar: rieles de metal recortados de una plancha u otros objetos, recortes con algún borde cóncavo y los cospeles cuadrangulares y redondeados producto de todo ello. 


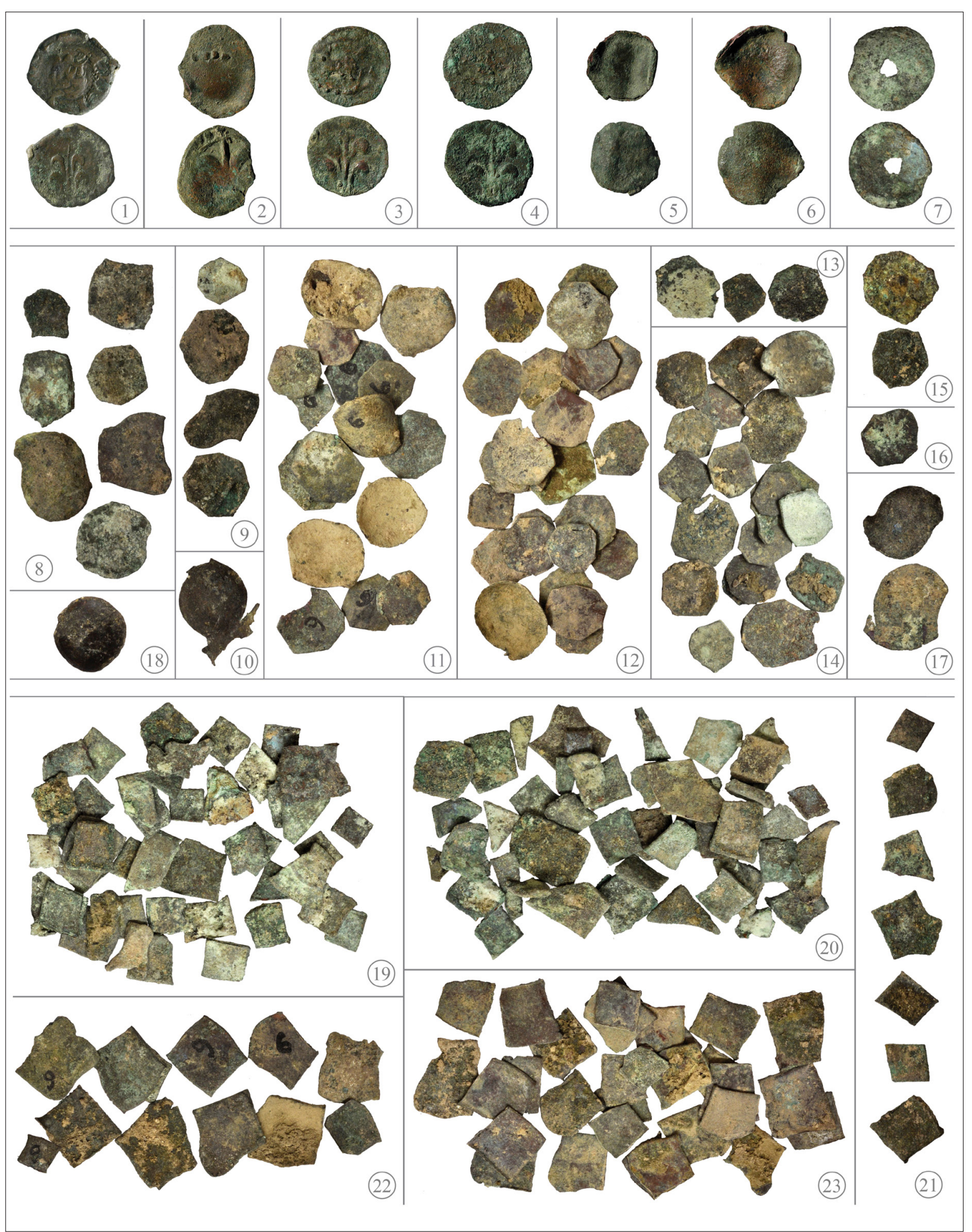

Fig. 3. Cueva de la Torre del Mal Paso: monedas (1-4), cospeles (5-18) y recortes (19-23). La numeración de las imágenes hace referencia a las entradas del catálogo. 


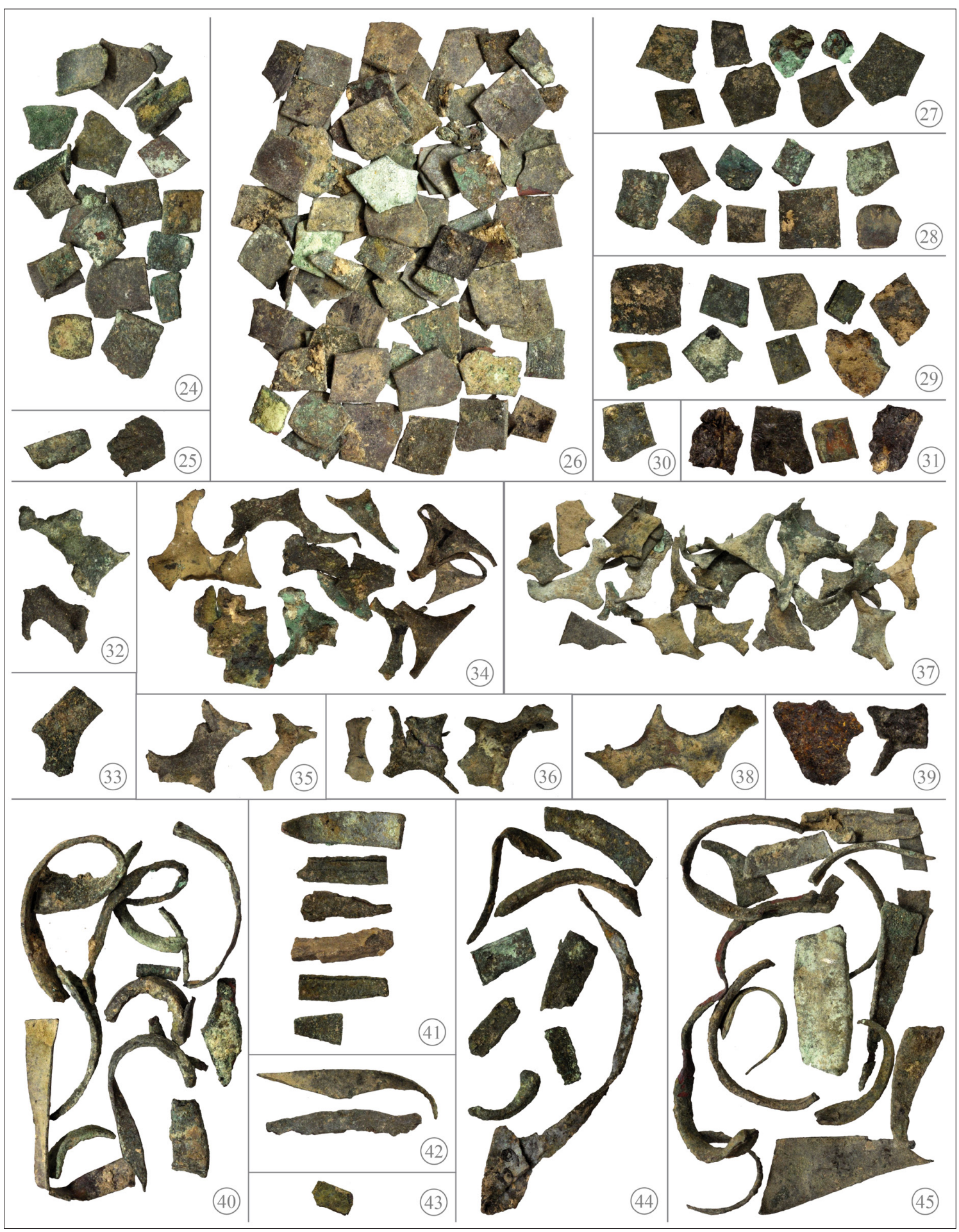

Fig. 4. Cueva de la Torre del Mal Paso: recortes (24-39) y rieles (40-45). La numeración de las imágenes hace referencia a las entradas del catálogo. 


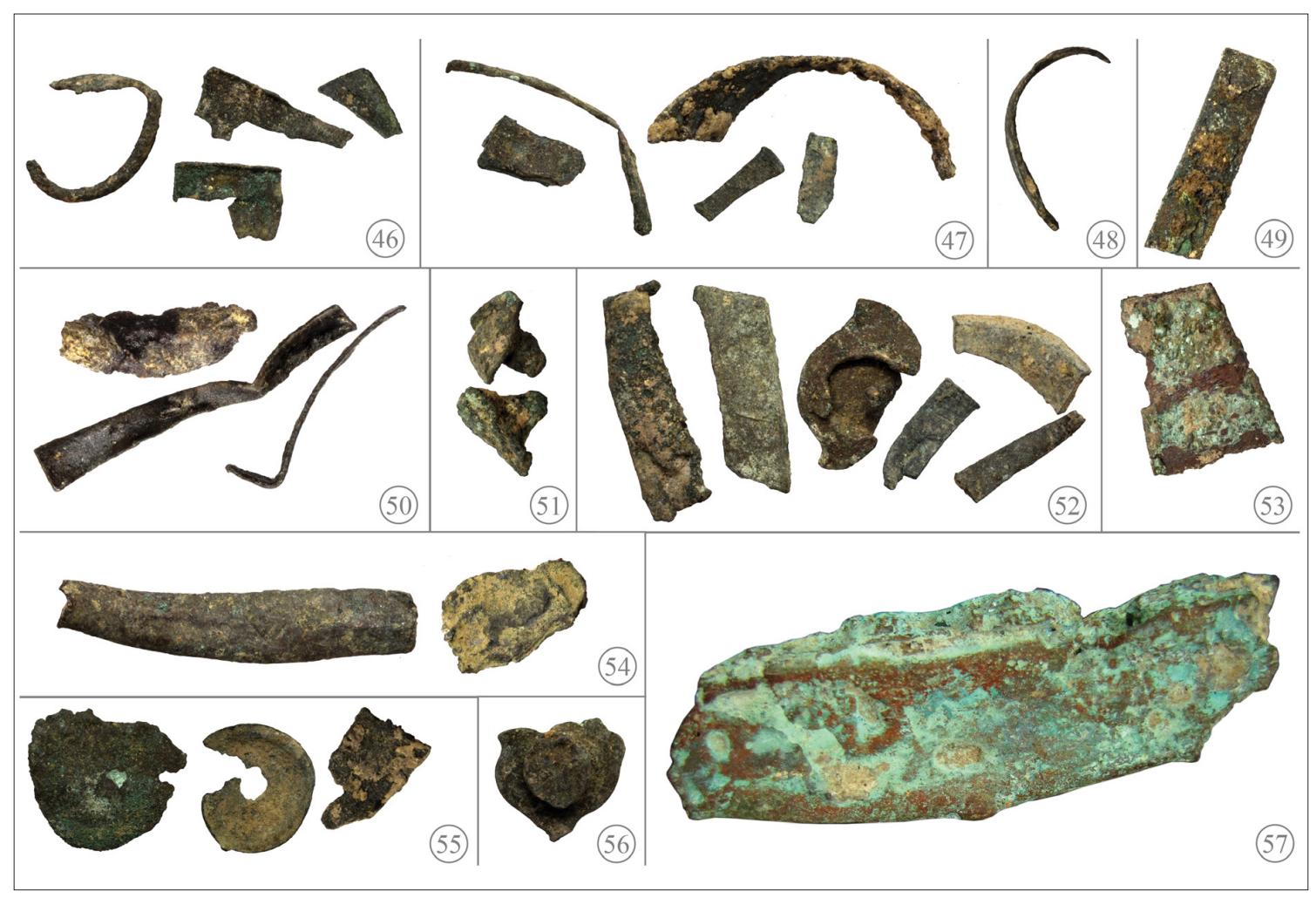

Fig. 5. Cueva de la Torre del Mal Paso: rieles (46-50) y objetos varios (51-57). La numeración de las imágenes hace referencia a las entradas del catálogo.

En la provincia actual de Valencia se conocen numerosas cuevas donde se falsificó moneda, como la Cova de l’Àguila (Ripollès 1993), la Cueva de la Soterraña de Chella (Mateu y Llopis 1954) o la Cova de l'Aigua de Simat (Toledo 1979), entre otras. En zonas cercanas al Mal Paso, además de los restos del Monte Zamora ya citados, se documenta el excepcional hallazgo de las tijeras de la Cueva de la Soterraña, al servicio de un taller de falsificación de moneda castellana (Mateu y Llopis 1954).

En el caso del Mal Paso, es posible que el trabajo de falsificación se realizara a la entrada de la cueva o bajo el orificio natural de la bóveda, ya que las características de la cavidad no parecen las óptimas para llevar a cabo este tipo de trabajos en su interior. La razón de que encontremos la mayor acumulación de restos de esta actividad en el fondo de la cueva (sector D) seguramente se deba a la pendiente que ésta presenta.

Las actividades delictivas de falsificación de moneda cuentan cada vez con mayor número de evidencias arqueológicas. Queda pendiente relacionarlas con la documentación valenciana de la época, que seguramente incluye numerosos testimonios inéditos sobre estas actividades fraudulentas. Los crecientes vestigios materiales corroboran la extensión de un fenómeno que constituyó un verdadero problema económico para las autoridades de la época.

\section{CATÁlogo}

\section{MONEDAS}

1) Valencia. ¿Felipe III-Felipe IV?. Diner. MPV 8023. Sin referencia. 11 h. 1,25 g

2) Valencia. Diner. Imitación. MPV 8024. Sin referencia. $0,74 \mathrm{~g}$

3) Valencia. Diner. Imitación. MPV 8025. Sin referencia. 7 h. $0,5 \mathrm{~g}$

4) Valencia. Diner. Imitación. MPV 8026. Sin referencia. $0,81 \mathrm{~g}$ 


\section{COSPELES}

5) Cospel. MPV 8027. Sin referencia. $0,6 \mathrm{~g}$

6) Cospel. MPV 8028. Sin referencia. 0,77 g

7) Cospel perforado. MPV 42283. Sector D. Nivel 2. $0,82 \mathrm{~g}$

8) 7 cospeles. MPV 42288. Sector D. Nivel 2.4,12 g 9) 4 cospeles. MPV 42294. Sector D. Nivel 7.1,91 g 10) Cospel con recorte inacabado. MPV 42296. Sector B. Niveles 1 y $2.0,87 \mathrm{~g}$

11) 16 cospeles. MPV 42300. Sector B. Niveles 1 y $2.7,29 \mathrm{~g}$

12) 24 cospeles. MPV 42303. Sector C. Nivel 1. 6,53 g

13) 3 cospeles. MPV 42306. Sector D. Nivel 4. 1,02 g

14) 20 cospeles. MPV 42315. Sector D. Nivel 1. 7,28 g

15) 2 cospeles. MPV 42317. Sector D. Nivel 8. $0,78 \mathrm{~g}$

16) Cospel. MPV 42322. Sector D. Nivel 5. 0,26 g

17) 2 cospeles. MPV 42328. Sector B. Nivel 3. 1,7 g

18) Cospel. MPV 42332. Varios niveles / Sin referencia. $0,75 \mathrm{~g}$

\section{RECORTES CUADRANGULARES}

19) 43 recortes. MPV 42287. Sector D. Nivel 2. 12,16 g 20) 47 recortes. MPV 42291. Sector D. Nivel 3. 12,77 g

21) 7 recortes. MPV 42293. Sector D. Nivel 7. 2,15 g

22) 12 recortes. MPV 42299. Sector B. Niveles 1 y 2. 6,28 g

23) 31 recortes. MPV 42302. Sector C. Nivel 1.9,21 g

24) 20 recortes. MPV 42305. Sector D. Nivel 4. 6,61 g

25) 2 recortes. MPV 42307. Sector E-C. Nivel 1. 0,46 g

26) 77 recortes. MPV 42314. Sector D. Nivel 1.29,88 g

27) 8 recortes. MPV 42316. Sector D. Nivel 8. 3,18 g

28) 9 recortes. MPV 42319. Sector D. Nivel 6.3,7 g

29) 9 recortes. 42321 . Sector D. Nivel $5.2,77 \mathrm{~g}$

30) Recorte. MPV 42325. Sector D. Nivel 9. 0,38 g

31) 4 recortes. MPV 42331. Varios niveles / Sin referencia. $1,58 \mathrm{~g}$

\section{RECORTES CON BORDES CÓNCAVOS}

32) 2 recortes. MPV 42286. Sector D. Nivel 2. 1,03 g

33) Recorte. MPV 42290. Sector D. Nivel 3. 0,61 g

34) 10 recortes. MPV 42298. Sector B. Niveles 1 y 2. 4,48 g

35) 2 recortes. MPV 42301. Sector C. Nivel 1.0,95 g

36) 3 recortes. MPV 42309. Sector E. Nivel 4. 0,97 g

37) 19 recortes. MPV 42313. Sector D. Nivel 1. 5,59 g

38) Recorte. MPV 42327. Sector B. Nivel 3. 0,92 g

39) 2 recortes. MPV 42330. Varios niveles / Sin referencia. $0,79 \mathrm{~g}$

\section{RIELES}

40) 14 rieles. MPV 42285. Sector D. Nivel 2.9,56 g

41) 6 rieles. MPV 42292. Sector D. Nivel 7. 2,41 g

42) 2 rieles. MPV 42297. Sector B. Niveles 1 y 2.0,68 g

43) Riel. MPV 42308. Sector E. Nivel 4. 0,38 g

44) 9 rieles. MPV 42310. Sector A. Nivel 4.5,48 g

45) 17 rieles. MPV 42312. Sector D. Nivel 1. 15,4 g

46) 1 riel y 3 recortes irregulares. MPV 42318. Sector D. Nivel 6. 1,45 g

47) 5 rieles. MPV 42320. Sector D. Nivel 5. 3,06 g

48) Riel. MPV 42324. Sector D. Nivel 9. 0,71 g

49) Riel. MPV 42326. Sector B. Nivel 3. 1,19 g

50) 3 rieles. MPV 42329. Varios niveles/Sin referencia. $2,55 \mathrm{~g}$

\section{VARIOS}

51) 2 remaches. MPV 42284. Sector D. Capa 2. 2,24 g

52) 5 barritas y una chapa. MPV 42289. Sector D. Nivel 3. $11,2 \mathrm{~g}$

53) Lámina cuadrangular. MPV 42295. Sector B. Niveles 1 y $2.2,29 \mathrm{~g}$

54) Barrita y chapa cuadrangular. MPV 42304. Sector A. Nivel 1. 5,24 g

55) 3 chapitas irregulares. MPV 42311. Sector D. Nivel 1. $3,03 \mathrm{~g}$

56) Botón o remache fracturado. MPV 42323. Sector D. Nivel 9. 2,4 g

57) Lámina. MPV 42333. Varios niveles / Sin referencia. $49,16 \mathrm{~g}$

Sonia Machause LóPeZ² Dept. Prehistòria i Arqueologia Universitat de València sonia.machause@uv.es

Manuel Gozalbes Fernández de Palencia Museu de Prehistòria de València Diputació Provincial de València manuel.gozalbes@dival.es

\section{NOTA}

1. MPV hace referencia al catálogo del Museu de Prehistòria de València.

2. Beneficiaria del programa de ayudas para la formación del personal investigador de carácter predoctoral, en el marco del Subprograma “Atracció de Talent" de la Universitat de València (VLC-CAMPUS) 


\section{BIBLIOGRAFÍA}

BALLESTER, I. (1946): Un donativo interesante al Museo de Prehistoria, APL II, 352.

BALLESTER, I. (1947): La labor del Servicio de Investigación Prehistórica y su Museo en el pasado año 1946, Diputación de Valencia.

BALLESTER, I. (1948): La labor del Servicio de Investigación Prehistórica y su Museo en el pasado año 1947, Diputación de Valencia.

BALLESTER, I. (1949): La labor del SIP y su Museo en los años 1940 a 1948, Valencia.

ESTRADA-RIUS, A. (2012): El desafío de la moneda falsa en la Barcelona de Felipe II (1598-1621), Sabadell.

FLETCHER, D. (1954): La cueva y el poblado de la Torre del Mal Paso (Castellnovo), APL V, 187-222.

JORDÁ, F. (1958): Los enterramientos de la Cueva de la Torre del Mal Paso (Castellnovo, Castellón), APL VII, 55-92.

LLUIS Y NAVAS-BRUSI, J.(1955): El delito de falsificación de moneda en los Fueros del Reino de Valencia, NVMISMA 15, 87-109.
MATEU Y LLOPIS, F. (1954): Para la historia monetaria del reinado de Felipe III (A propósito de una falsificación de "quartos"), NVMISMA 12, 49-56.

MATEU Y LLOPIS, F. (1955): Hallazgos monetarios XII, Numario Hispánico IV, 119-146.

RIPOLLÈS, P. P. (1993): La cova de L'Aguila: un taller de falsificadores de moneda (siglo XVII), NVMISMA 43 (233), 261-293.

SENDRA, J. A.; RODRIGO, J. A. (2010-2011): Un nou taller de falsificació de billó valencià. Monte Zamora a la Vall d'Uixò (Castelló), Acta Numismàtica 41/42, 225-235.

SOLER DÍAZ, J. A. (2002): Cuevas de inhumación múltiple en la Comunidad Valenciana, Real Academia de la Historia, Diputación Provincial de Alicante.

TOLEDO, J. (1979): Encunyació de moneda falsa a La Cova de l'Aigua, D. Y. A. (Revista del Centre Excursionista de Tavernes de la Valldigna), 22-23.

TORRES, J. (2012): La falsificació de moneda a l'edat moderna, La moneda falsa. De l'antiguitat a l'euro, (A. Estrada-Rius dir.), Barcelona, 74-81. 